\title{
Recent Walker Circulation strengthening and Pacific cooling amplified by Atlantic warming
}

\author{
Shayne McGregor ${ }^{1}$, Axel Timmermann ${ }^{2 *}$, Malte F. Stuecker ${ }^{3}$, Matthew H. England ${ }^{1}$, Mark \\ Merrifield $^{4}$, Fei-Fei Jin $^{3}$, Yoshimitsu Chikamoto ${ }^{2}$ \\ ${ }^{1}$ ARC Centre of Excellence for Climate System Science, UNSW, Sydney, Australia \\ ${ }^{2}$ International Pacific Research Center, SOEST, University of Hawaii, Honolulu, USA \\ ${ }^{3}$ Department of Meteorology, SOEST, University of Hawaii, Honolulu, USA \\ ${ }^{4}$ Department of Oceanography, SOEST, University of Hawaii, Honolulu, USA \\ *Correspondence to: axel@hawaii.edu
}

An unprecedented strengthening of Pacific Trade Winds since the late $1990 \mathrm{~s}^{1}$ has caused wide-spread climate perturbations, including rapid sea level rise in the western tropical Pacific $^{2-5}$, strengthening of Indo-Pacific ocean currents ${ }^{6,7}$, and an increased uptake of heat in the equatorial Pacific thermocline ${ }^{1}$. The corresponding intensification of the atmospheric Walker Circulation is also associated with sea surface cooling in the eastern Pacific, which has been identified as one of the contributors to the current pause in global surface warming ${ }^{1,8,9}$. In spite of recent progress in determining the climatic impacts of the Pacific Trade Wind acceleration, the cause of this pronounced trend in atmospheric circulation remains unknown. Here we analyze a series of climate model experiments along with observational data to show that the recent Atlantic sea surface temperature warming trend and the corresponding trans-basin displacements of the main atmospheric pressure centers were key drivers of the observed Walker Circulation intensification, eastern Pacific cooling, North American rainfall trends and western Pacific sea level rise. Our study suggests that global surface warming has been partly offset by the Pacific climate response to enhanced Atlantic warming since the early 1990s. 
Given the importance of the recent wind-induced trends in Pacific sea level and surface temperature, it is vital to determine the underlying causes. Recent studies have focused mostly on the low frequency Pacific climate modes, such as the Pacific Decadal Oscillation ${ }^{10}$ (PDO) or the Interdecadal Pacific Oscillation ${ }^{11}$ (IPO) to explain Pacific wind shifts and the current pause in greenhouse warming ${ }^{8,9,12}$. However, the fact that this unprecedented 1992-2011 equatorial Pacific zonal wind trend ${ }^{1}$ is not consistent with a Pacific-only sea surface temperature (SST) driving mechanism ${ }^{5}$ suggests a role for dynamics outside the tropical Pacific in this atmospheric reorganization, such as from the Indian Ocean ${ }^{5,13}$, the Atlantic ${ }^{14}$ or both. This scenario is further supported by the fact that the Trade Wind intensification since the early 1990s is related to a global scale see-saw in atmospheric surface pressure, which is characterized by a positive sea level pressure (SLP) trend in the Pacific and a negative trend in the Indo-Atlantic region (Fig. 1a). Our study uses a series of climate model experiments in combination with observational analyses to identify potential remote drivers of Pacific equatorial wind changes since the early 1990s and their corresponding impacts on global climate.

We first conduct a suite of 5 member ensemble of sensitivity experiments using the Community Atmospheric Model, version 4 (CAM4) atmospheric general circulation model (AGCM) (see Methods and Table S1) to further elucidate the underlying physical mechanism of the recent inter-basin SLP see-saw (Fig 1a) and its corresponding effects on the Pacific Trade Wind systems. We prescribe the trend in observed global SST anomalies (SSTA) over the period 19922011 (Fig. 1a), which is characterized by an overall Atlantic warming, an eastern Pacific cooling trend and western subtropical Pacific and Indian Ocean warming. This pattern is in fact quite different from the typical global warming hiatus pattern simulated by Coupled General 
Circulation Models ${ }^{9}$, which exhibits similar cooling trends across all tropical oceans. In response to the applied global SST trend forcing the AGCM experiment reproduces the observed global SLP see-saw, and the related intensification of tropical Pacific Trade Winds qualitatively well (Fig. 1c,d, Fig. S1 g,h, Fig S3a).

It is important to note that in spite of capturing the overall sea level pressure and wind trend patterns (Figs. $1 \mathrm{c}, \mathrm{d}, \mathrm{S} 1 \mathrm{~g}, \mathrm{~h}$ ), the CAM4 ensemble mean underestimates the magnitude of the central Pacific wind stress intensification by a factor of 3 (Table S2). The magnitude of the underestimated wind stress response of these AGCM ensemble simulations is consistent with the weaker surface Trade Wind response for this period simulated by an ensemble of 25 models of SST anomaly-forced AGCM experiments conducted as part of the Atmospheric Model InterComparison, version 5, (AMIP5) (See supplementary Information, Fig. S1 c,e \& S2a). It should be noted here, that the simulated AMIP5 trends in zonal $850 \mathrm{hPa}$ winds (Fig. S1 d,f, Table S3) are much more consistent with the reanalysis data than the surface stresses, thus indicating AGCM deficiencies in the downward mixing of momentum through the boundary layer.

Next we carry out a series of CAM4 simulations, each with 5 ensemble members, with prescribed sea surface temperature forcing in some ocean areas and a slab mixed layer ocean in others to isolate the effect of different ocean basins on the Pacific Trade Wind intensification (see Methods and Table S1). The origin of the recent Pacific climate trends becomes apparent in the ensemble AGCM experiment that is forced only by Atlantic SSTA trends while using a mixed layer ocean in the Pacific, and prescribed climatological SST in the Indian Ocean (See supplementary Information, Table S1). In this experiment the global atmosphere and Pacific 
SSTs can adjust to the remote observed Atlantic SSTA trend forcing. The ensemble mean results of this experiment demonstrate that the recent Atlantic warming generates a trans-basin (Pacific/Atlantic) SLP see-saw that is very similar to the observations (Fig. 1e and S3b). This generates a significant strengthening of the wind stress in the central Pacific (Fig. 1f), which can account on average for $90 \%$ of the trends simulated by the AGCM simulation forced by the observed SST trend everywhere (Fig. 1c and Table S2). The intensification of the Pacific trade winds in turn generates eastern tropical Pacific cooling (Fig. 1e) that closely resembles the observations (Fig. 1a); along with the negative phase of the PDO/IPO, which has been invoked previously to explain the recent global warming hiatus period ${ }^{12}$. Furthermore, we note that the precipitation response to the eastern Pacific cooling in the Atlantic SST-forced experiment (Fig. 1f) closely resembles recent trends in observed precipitation ${ }^{7}$ (Fig. 1b), including the severe drought in the Southwestern United States.

In order to better understand the dynamics of this trans-basin SLP see-saw, and the role of coupled Pacific air-sea interactions, CAM4 is forced in a third experiment with SSTA trends only in the Atlantic basin, however in this case both the Pacific and Indian ocean are subject to climatological SST forcing (no Pacific Ocean slab mixed layer) (Table S1). The trans-basin SLP see-saw response in this experiment (Fig. S4d) is qualitatively similar to the previous experiment which employed an active Pacific mixed layer (Fig. S4c), but the central/eastern equatorial Pacific pressure lobe is approximately half the magnitude (Fig. S3b). The vertical atmospheric velocity on the equator reveals that the Atlantic basin SSTA trend alone leads to upward motion over most of the Atlantic region and descending motion in the central-to-eastern equatorial Pacific (Fig. 2a). This directly links SSTs in the Atlantic region with the Pacific Ocean Walker 
circulation consistent with earlier studies ${ }^{14,15}$. Allowing for Pacific air-sea thermal coupling (Fig. 2b), and in particular the wind-evaporation SST feedback, the experiment with an active Pacific mixed layer generates stronger Pacific basin subsidence and an enhancement of the Walker circulation, in agreement with the global SST trend simulation (Fig. 2c) and the ERA40 reanalysis (Fig. 2d).

We also carry out a 5 member ensemble of CAM4 experiments that are forced only by Indian Ocean SSTA trends while using a mixed layer ocean in the Pacific, and prescribed climatological SST in the Atlantic Ocean (See supplementary Information, Table S1). The ensemble mean results of this experiment do not show a considerable trans-basin SLP see-saw and no significant wind stress anomalies in equatorial Pacific (Fig. S3c, S5 and Table S2) in contrast to recent studies $^{5,13}$ that have proposed a more active role of Indian Ocean SST trends in causing Pacific Trade Wind changes.

The comparison of the simulated Pacific SST trends in the Atlantic SST/Pacific mixed layer experiment (Fig 1e,f) with observations (Fig 1a,f) documents that the current Pacific Trade Wind strengthening and decadal cooling in the eastern Pacific, which contributes to the ongoing global warming hiatus ${ }^{8}$ and to the high rate of sea level rise in the western tropical Pacific $^{2}$, can not be solely caused by internally generated Pacific Ocean variability. Our results highlight instead the importance of a recent rapid Atlantic warming ${ }^{16}$ seen since the 1990s and the ensuing AtlanticPacific interactions (Fig. 1). This finding is consistent with recent modeling studies that identified a tight physical linkage between Atlantic and Pacific climate variability on decadal timescales ${ }^{14,15,17-21}$ and between Atlantic Ocean and mean Northern Hemisphere temperatures ${ }^{19}$. 
Additional Atlantic SST sensitivity experiments with CAM4 show that the spatially averaged Atlantic SSTA trend (Fig. S6 c,d) and to a lesser degree its corresponding gradient component (with the spatially averaged Atlantic SST trend removed, Fig. S6 a,b) both contribute to the observed equatorial wind stress and SLP shifts. Furthermore, in a simulation forced with the Pacific SSTA trend/Atlantic mixed layer we find that the current Pacific SSTA trend acts to warm North Atlantic Ocean SSTs (Fig. S7), indicating a potential trans-basin positive feedback. Thus, Pacific SSTA trends also play an important role in controlling the trans-basin SSTA and SLP gradients.

To further characterize the dynamics of this Trans-Basin Variability (TBV), we define a basinscale TBV SST index (Fig. 3b) as the monthly mean difference timeseries of Atlantic-Pacific SSTA (spatial average over $30^{\circ} \mathrm{S}-60^{\circ} \mathrm{N}, 70^{\circ} \mathrm{W}-20^{\circ} \mathrm{E}$ and $30^{\circ} \mathrm{S}-60^{\circ} \mathrm{N}, 120^{\circ} \mathrm{E}-90^{\circ} \mathrm{W}$, respectively). The correlation between the 11-month running mean TBV SST index and the Atlantic and Pacific basin averaged interannual to multidecadal SSTA attains values of 0.66 and -0.37 , respectively (Table S4), indicating that Atlantic SSTAs play the dominant role in controlling the TBV. The unfiltered TBV SST index is clearly related to the Pacific Trade Wind strength (Fig. 3b) and displays pronounced decadal variability, and a spectral damping timescale of about 5 years (Fig. S8) that translates into multi-year damped persistence skill. As a result of relatively cold Atlantic conditions after the Mt. Pinatubo eruption in 1991 and a warm Pacific with a long lasting El Niño event in the early 1990s, the TBV index was anomalously negative and the Pacific Trade Winds were anomalously weak (Fig. 3). The subsequent recovery and rapid Atlantic warming ${ }^{16}$ and cooling of the eastern Pacific reversed this gradient, reaching maximum values around $\sim 2010-2012$ (Fig. 3a). Consistent with the modeling results, these SSTA trends 
caused anomalous low pressure over the Atlantic and higher pressure in the eastern Pacific (Fig. 1e, 3b), which in turn enhanced easterly Trade Winds in the central tropical Pacific (Fig. 1f, 3b) as well as in off-equatorial regions. The TBV-related wind pattern subsequently played a significant role in the rapid sea-level acceleration in the western tropical Pacific ${ }^{2}$. Although the proposed trans-basin coupling mechanism successfully explains recent observed trends in Pacific climate (Fig. 3b) since the early 1990s and as documented by the CAM4 sensitivity experiments, it is clearly not the main driver for the multidecadal acceleration and deceleration of global surface warming prior to this period, as illustrated by the insignificant correlation between TBV and the detrended global mean SST signal (Table S4).

By comparing the recent 20-yr trend (1992-2011) in the TBV SST index with long-term SST observations (Fig. 4a), we find that the former is unprecedented in the context of the 1872-1992 observations $^{22}$ (Fig. 4a). For the 1992-2011 trans-basin SLP trend (Fig. 4b) similarly low probabilities are identified with values below $0.27 \%$ (a 3 standard deviation $(\sigma)$ event, NCEP2 ${ }^{23}$ SLP data) and $0.034 \%\left(4.5 \sigma\right.$ event, $20^{\text {th }}$ Century Reanalysis ${ }^{24}$ SLP data). Comparing the former with overlapping 20-year TBV trends in historical runs (1861-1980 CE, including greenhouse gas, aerosol, volcanic and solar forcings) and RCP8.5 Coupled General Circulation Model experiments (1981-2100), conducted as part of the Coupled Model Intercomparison Project ${ }^{25}$ phase 5, it is found that the current trans-basin SST trend exceeds $3.5 \sigma$ of the simulated overlapping 20-year model trends. These results and our global SST-forced CAM4 and AMIP5 model analyses are indicative of a systematic underestimation of atmospheric trans-basin connections on decadal timescales in the current generation of climate models. However, as 
noted above, issues with the downward mixing of momentum through the atmospheric boundary layer are likely to play some role in this underestimation.

Our findings reveal that rapid Atlantic warming since the early 1990s led to an unusually rapid acceleration of the Pacific Trade Wind systems (Fig. 1e). Recent studies ${ }^{1,12}$ document that the corresponding tropical Pacific cooling, along with other processes, contributed to the observed decadal slowdown of global surface warming trends. We further demonstrated that trans-basin coupled atmosphere/ocean variability explains part of the recent decadal rainfall trends across the Pacific, including the severe California drought conditions. It is suggested that pronounced spectral power of the trans-basin variability index on decadal timescales as well as the long damping timescale (Fig. 3, S8), may translate into multi-year predictive skill ${ }^{17}$. 


\section{Figure Legends}

Fig. 1: Trends (1992-2011) of SST, SLP, wind stress and relative precipitation a) Observed surface temperature $^{26}$ [C/year] (shading) and $\mathrm{SLP}^{27}$ [Pa/year] (contour); SLP trend contours range from -14 $\mathrm{Pa}$ to $14 \mathrm{~Pa}$ with a contour level of $4 \mathrm{~Pa}$; negative contours are dashed. SLP significance levels are represented as stippling in Fig. S4; b) Observed relative precipitation trends (shading) and wind stress trends ${ }^{27}$ significant above the $95 \%$ level (vector). In both panels stippling indicates that the changes in the underlying shaded plots are significant above the $95 \%$ level; c) as in a), and d) as in b) but for CAM4 experiment forced with global observed SST trend (shading); e) as in a), and f) as in b), but for CAM4 experiment forced with Atlantic SST trend and Pacific mixed layer.

Fig 2: a) Vertical equatorial atmospheric velocity trends ( $\mathrm{Pa} \mathrm{s}^{-1} /$ year, shading) over the 19922011 period from the CAM4 experiment forced with Atlantic SST trend, where SSTs are set to climatology in the Pacific and Indian Oceans. Overlying vectors represent the zonal wind trend and the vertical velocity scaled by a factor 300 . b) as in a) but for the for CAM4 experiment forced with the observed Atlantic Ocean SST trend and Pacific mixed layer; c) as in a) but for the for CAM4 experiment forced with the global observed SST trend and Pacific mixed layer. d) same as a) but for the ERA-interim reanalysis.

Fig. 3: Atlantic and Pacific SST anomalies and their effect on SLP anomaly and wind anomalies: a) Basin averaged Atlantic (orange, $30^{\circ} \mathrm{S}-60^{\circ} \mathrm{N}, 70^{\circ} \mathrm{W}-20^{\circ} \mathrm{E}$ ) and Pacific (cyan, $30^{\circ} \mathrm{S}-60^{\circ} \mathrm{N}$, $\left.120^{\circ} \mathrm{E}-90^{\circ} \mathrm{W}\right) \mathrm{SST}$ anomalies from $\mathrm{ERSST}^{22}$; the solid red and blue lines represent 11-month running mean values of Atlantic and Pacific basin SST anomalies, respectively. b) detrended 
SST anomaly difference (shading) (11-month running mean TBV index) between the red and blue timeseries in upper panel, western tropical Pacific $\left(160^{\circ} \mathrm{E}-180^{\circ} \mathrm{E}\right.$ and $\left.5^{\circ} \mathrm{S}-5^{\circ} \mathrm{N}\right)$ detrended zonal surface wind velocity anomalies (black line) from $20^{\text {th }}$ Century Reanalysis ${ }^{24}$ (11-month running mean filter), and the 11 month running mean of the detrended Atlantic/Pacific SLP anomaly difference ${ }^{24}$ (cyan, same areas as for SST). The table inset in b) displays the correlation coefficients calculated across the three displayed time series.

Fig. 4: a) Normalized histogram of 20-year trends of the Trans-Basin Variability (TBV) SST index for the observations (ERSST ${ }^{22}$ ) pre 1991 (dashed black), $3920^{\text {th }}$ century CMIP5 experiments (blue) and RCP8.5 experiments (1981-2100). The recent 1992-2011 value using the ERSST $^{22}$ dataset is indicated by a black bar; b) same as a) but for the TBV SLP index (SLP averaged in $30^{\circ} \mathrm{S}-60^{\circ} \mathrm{N}, 70^{\circ} \mathrm{W}-20^{\circ} \mathrm{E}$ minus SLP in $30^{\circ} \mathrm{S}-60^{\circ} \mathrm{N}, 120^{\circ} \mathrm{E}-90^{\circ} \mathrm{W}$ ) and using the observational SLP data estimated from the $20^{\text {th }}$ Century reanalysis ${ }^{24}$. Black and yellow bars represent the recent 1992-2012 trends from the 20th Century ${ }^{24}$ and the NCEP2 reanalysis ${ }^{23}$, respectively. 


\section{Methods Summary}

To determine the effects of recent basin-wide Sea Surface Temperature (SST) trends on the atmospheric circulation and on SSTs in other ocean basins we utilize the CAM4 Atmospheric General Circulation Model (AGCM) in T42 horizontal resolution with 26 vertical layers ${ }^{28}$ in a series of AGCM and partially coupled AGCM sensitivity experiments (Table S1). The AGCM experiments have SST prescribed everywhere. The prescribed SSTs incorporate a climatological SST forcing ${ }^{29}$ component in combination with SST trends in specified regions. In the suite of partially coupled AGCM experiments, we prescribe the 1992-2011 SST trend in some basins while allowing the ocean in the other basin/basins to integrate the atmospheric heat fluxes using a slab ocean thermodynamic mixed layer (ML) model. In these partially coupled experiments CAM4 is coupled to the $\mathrm{ML}^{30}$, which includes spatially varying annual mean mixed layer depths. A detailed description of the experimental setup is provided in the Supplementary Information. 


\section{References}

1 England, M. et al. Recent intensification of wind-driven circulation in the Pacific and the ongoing warming hiatus, Nature Cimate Change, DOI: 10.1038/NCLIMATE2106, (2014).

2 Timmermann, A., McGregor, S. \& Jin, F. F. Wind Effects on Past and Future Regional Sea Level Trends in the Southern Indo-Pacific. Journal of Climate 23, 4429-4437, doi:10.1175/2010jcli3519.1 (2010).

3 McGregor, S., Sen Gupta, A. \& England, M. H. Constraining Wind Stress Products with Sea Surface Height Observations and Implications for Pacific Ocean Sea Level Trend Attribution. Journal of Climate 25, 8164-8176, doi:10.1175/jcli-d-12-00105.1 (2012).

4 Nidheesh, A. G., Lengaigne, M., Vialard, J., Unnikrishnan, A. S. \& Dayan, H. Decadal and long-term sea level variability in the tropical Indo-Pacific Ocean. Climate Dynamics 41, 381-402, doi:10.1007/s00382012-1463-4 (2013).

5 Han, W. et al. Intensification of decadal and multi-decadal sea level variability in the western tropical Pacific during recent decades Clim. Dyn. DOI 10.1007/s00382-00013-01951-00381 (2013).

6 Feng, M. et al. The reversal of the multi-decadal trends of the equatorial Pacific easterly winds, and the Indonesian Throughflow and Leeuwin Current transports. Geophysical Research Letters 38, doi:10.1029/2011gl047291 (2011).

7 Merrifield, M. A. \& Maltrud, M. E. Regional sea level trends due to a Pacific Trade Wind intensification. Geophysical Research Letters 38, doi:10.1029/2011gl049576 (2011).

8 Kosaka, Y. \& Xie, S. P. Recent global-warming hiatus tied to equatorial Pacific surface cooling. Nature 501, 403-+, doi:10.1038/nature12534 (2013).

9 Meehl, G. A., Hu, A. X., Arblaster, J. M., Fasullo, J. \& Trenberth, K. E. Externally Forced and Internally Generated Decadal Climate Variability Associated with the Interdecadal Pacific Oscillation. Journal of Climate 26, 7298-7310, doi:10.1175/jcli-d-12-00548.1 (2013).

10 Mantua, N. J., Hare, S. R., Zhang, Y., Wallace, J. M. \& Francis, R. C. A Pacific interdecadal climate oscillation with impacts on salmon production. Bulletin of the American Meteorological Society 78, 10691079, (1997).

11 Power, S., Casey, T., Folland, C., Colman, A. \& Mehta, V. Inter-decadal modulation of the impact of ENSO on Australia. Climate Dynamics 15, 319-324, doi:10.1007/s003820050284 (1999).

12 Trenberth, K. E. \& Fasullo, J., T. (Earth's Future, 2013).

13 Luo, J. J., Sasaki, W. \& Masumoto, Y. Indian Ocean warming modulates Pacific climate change. Proceedings of the National Academy of Sciences of the United States of America 109, 18701-18706, doi:10.1073/pnas.1210239109 (2012).

14 Kucharski, F., Kang, I. S., Farneti, R. \& Feudale, L. Tropical Pacific response to 20th century Atlantic warming. Geophysical Research Letters 38, doi:10.1029/2010g1046248 (2011).

15 Wang, C. Z. An overlooked feature of tropical climate: Inter-Pacific-Atlantic variability. Geophysical Research Letters 33, doi:10.1029/2006g1026324 (2006).

16 Robson, J., Sutton, R. \& Smith, D. Predictable climate impacts of the decadal changes in the ocean in the 1990s (vol 26, pg 6329, 2013). Journal of Climate 26, 9207-9207, doi:10.1175/jcli-d-13-00512.1 (2013).

17 Chikamoto, Y., Kimoto, M., Watanabe, M., Ishii, M. \& Mochizuki, T. Relationship between the Pacific and Atlantic stepwise climate change during the 1990s. Geophysical Research Letters 39, doi:10.1029/2012gl053901 (2012).

18 Dong, B. W. \& Lu, R. Y. Interdecadal enhancement of the Walker circulation over the Tropical Pacific in the late 1990s. Advances in Atmospheric Sciences 30, 247-262, doi:10.1007/s00376-012-2069-9 (2013).

Zhang, R. \& Delworth, T. L. Impact of the Atlantic Multidecadal Oscillation on North Pacific climate variability. Geophysical Research Letters 34, L23708, doi:10.1029/2007g1031601 (2007).

20 Hong, S., Kang, I. S., Choi, I. \& Ham, Y. G. Climate responses in the tropical pacific associated with atlantic warming in recent decades. Asia-Pacific Journal of Atmospheric Sciences 49, 209-217, doi:10.1007/s13143-013-0022-1 (2013).

21 Timmermann, A., Latif, M., Voss, R. \& Grötzner, A. Northern Hemispheric interdecadal variability: A coupled air-sea mode. Journal of Climate 11, 1906-1931, doi:10.1175/1520-0442-11.8.1906 (1998).

22 Reynolds, R. W., Rayner, N. A., Smith, T. M., Stokes, D. C. \& Wang, W. Q. An improved in situ and satellite SST analysis for climate. Journal of Climate 15, 1609-1625, (2002). 
Kanamitsu, M. et al. NCEP-DOE AMIP-II reanalysis (R-2). Bulletin of the American Meteorological Society 83, 1631-1643, doi:10.1175/bams-83-11-1631 (2002).

24 Compo, G. P. et al. The Twentieth Century Reanalysis Project. Quarterly Journal of the Royal Meteorological Society 137, 1-28, doi:10.1002/qj.776 (2011).

25 Taylor, K. E., Stouffer, R. J. \& Meehl, G. A. AN OVERVIEW OF CMIP5 AND THE EXPERIMENT DESIGN. Bulletin of the American Meteorological Society 93, 485-498, doi:10.1175/bams-d-11-00094.1 (2012).

26 Hansen, J., Ruedy, R., Sato, M. \& Lo, K. GLOBAL SURFACE TEMPERATURE CHANGE. Reviews of Geophysics 48, doi:10.1029/2010rg000345 (2010).

27 Dee, D. P. et al. The ERA-Interim reanalysis: configuration and performance of the data assimilation system. Quarterly Journal of the Royal Meteorological Society 137, 553-597, doi:10.1002/qj.828 (2011).

28 Neale, R. B. et al. Vol. 26 5150-5168 (J. Climate, 2013).

29 Hurrell, J. W., Hack, J. J., Shea, D., Caron, J. M. \& Rosinski, J. A new sea surface temperature and sea ice boundary dataset for the Community Atmosphere Model. Journal of Climate 21, 5145-5153, doi:10.1175/2008jcli2292.1 (2008).

30 Kiehl, J. T., Shields, C. A., Hack, J. J. \& Collins, W. D. The climate sensitivity of the Community Climate System Model version 3 (CCSM3). Journal of Climate 19, 2584-2596, doi:10.1175/jcli3747.1 (2006).

\section{Acknowledgements}

This work was supported by the Australian Research Council (ARC) including the ARC Centre of Excellence in Climate System Science. AT was supported through NSF grant No. 1049219. MFS and FFJ were supported by US NSF grant ATM1034798, US Department of Energy grant DESC005110, US NOAA grant NA10OAR4310200. The AVISO altimeter products were produced by the CLS Space Oceanography Division as part of the Environment and Climate EU ENACT project (EVK2-CT2001-00117) and with support from CNES.

\section{Author Contributions:}

SM and AT conceived the study and wrote the initial manuscript draft. AT analysed observational and CMIP5 data, MFS conducted the AGCM and partially coupled model simulations, SM analysed the model output and the AMIP5 simulations. All authors contributed to interpreting the results, discussion of the associated dynamics, and refinement of the paper. 
(a) CAM4 exp - AO SST trend only

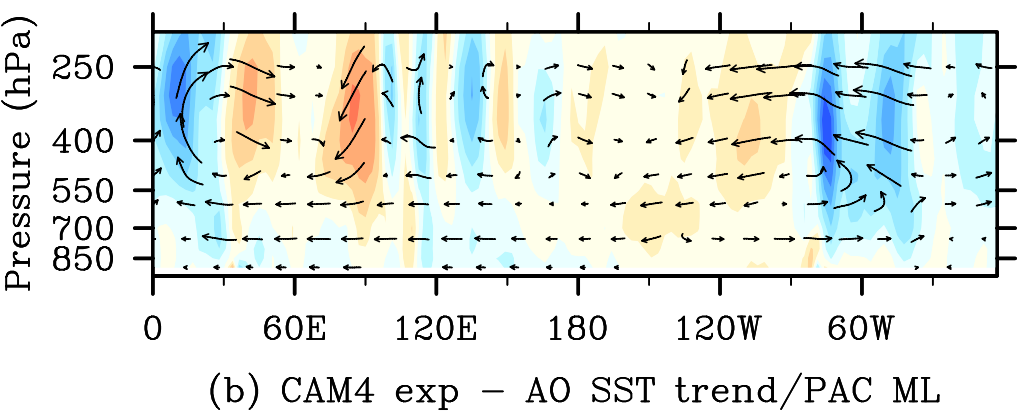

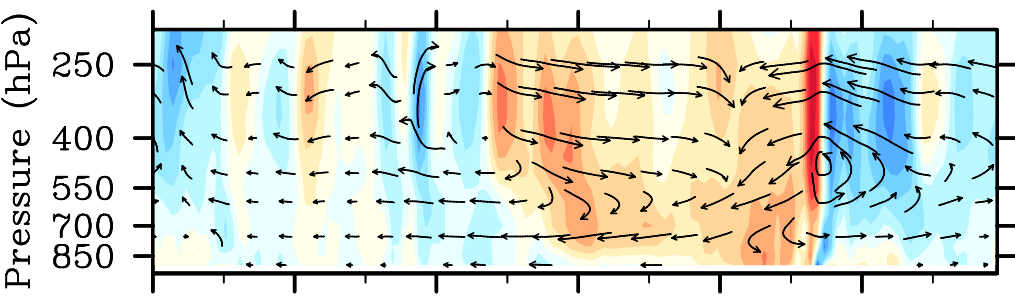

0 60E 120E 180 120W 60W

(c) CAM4 exp - Global SST trend

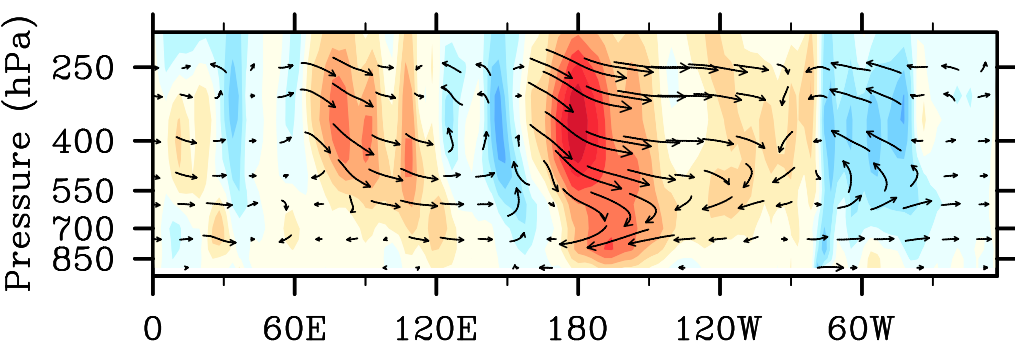

(d) Observed (ERA-interim)

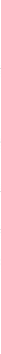

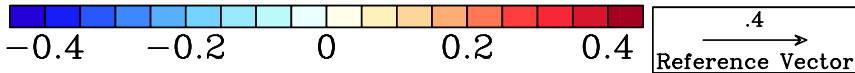




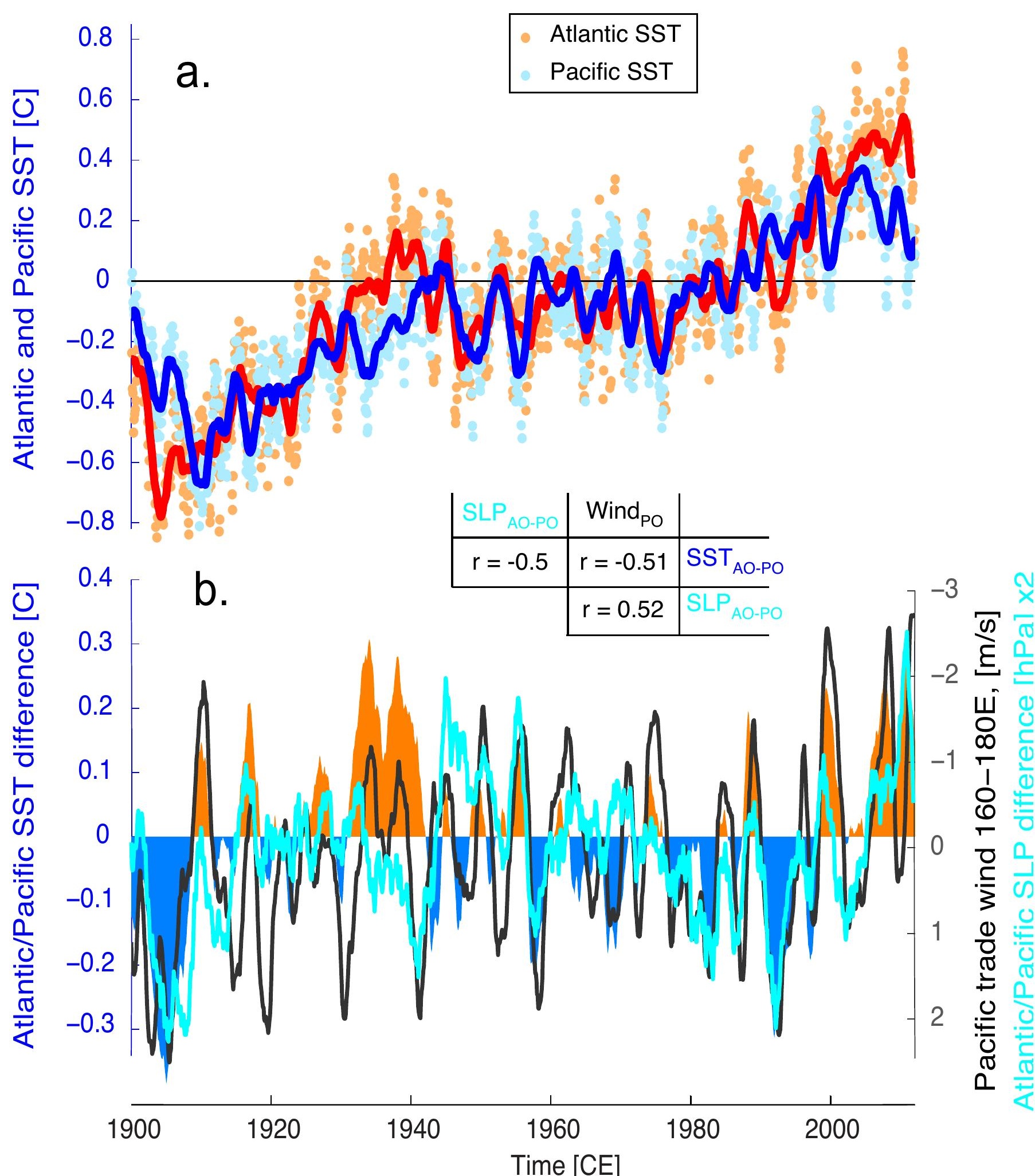




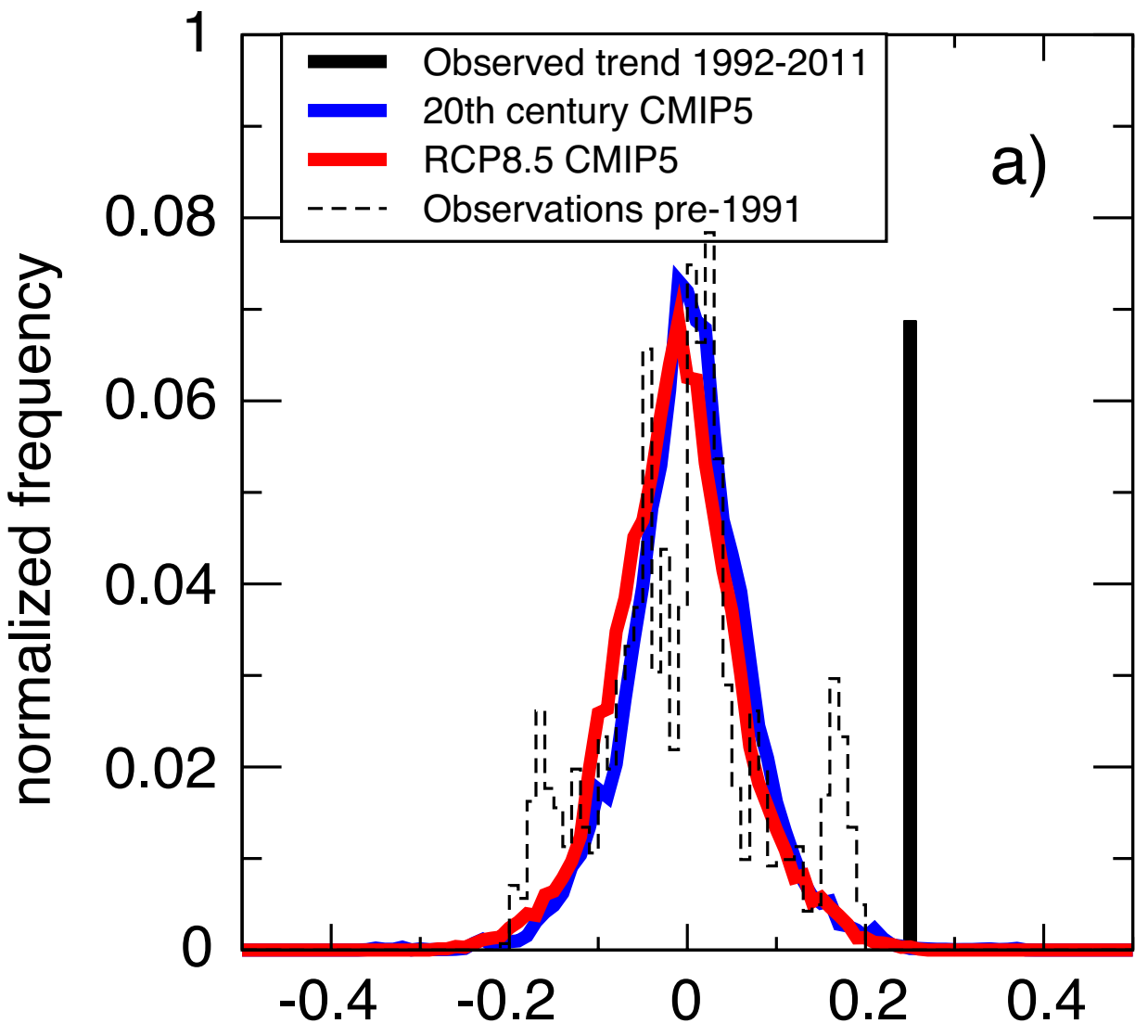

TBV SST 20-yr trend [C/decade]

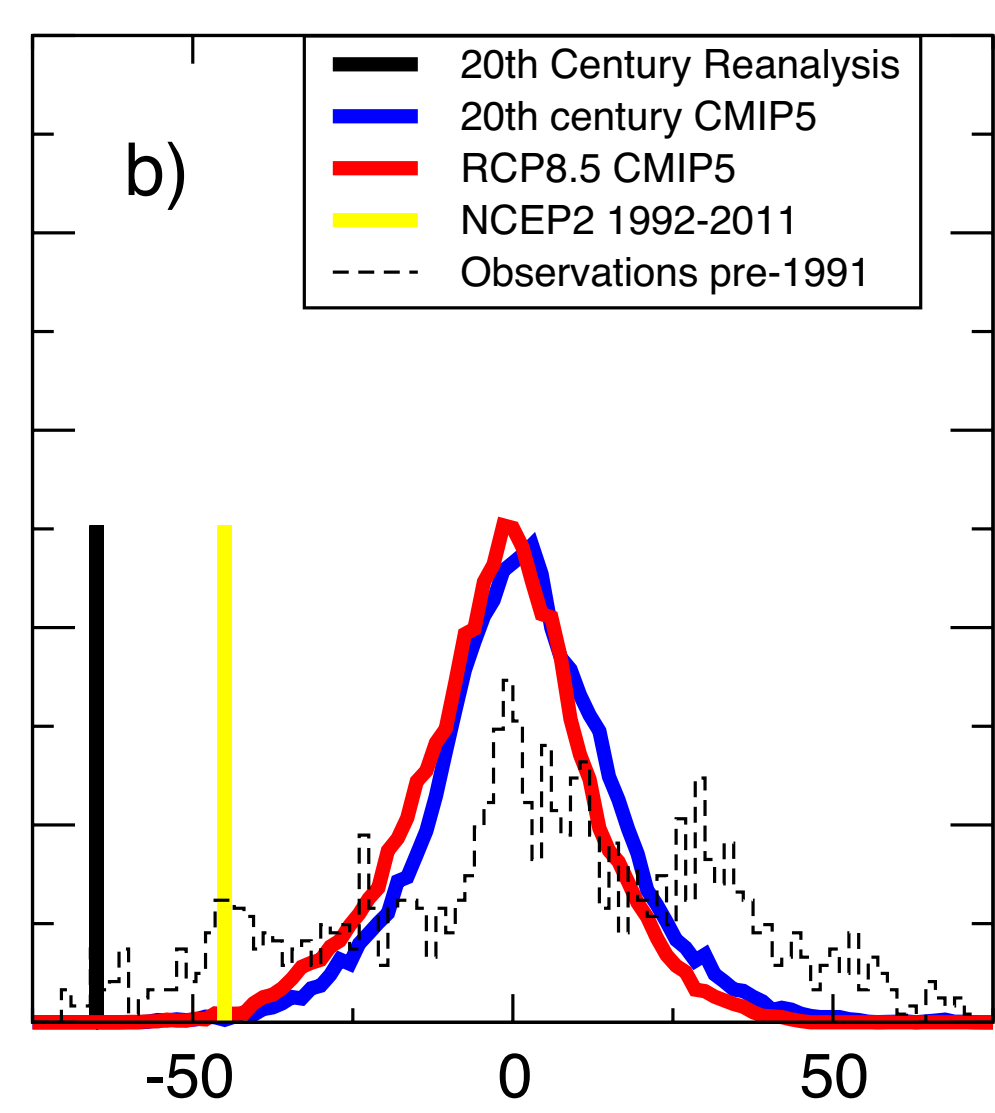

TBV SLP 20-yr trend [Pa/decade] 